\title{
RENDIMIENTO PRODUCTIVO, NITRÓGENO Y FIBRA CRUDA DEL FORRAJE DE BOLAINA BLANCA (GUAZUMA SP.) CULTIVADA COMO BANCO DE PROTEÍNA, EN SATIPO*
}

\author{
Bazán A. Luis ${ }^{1}$ y Granados M. Maria ${ }^{2}$
}

Facultad de Ciencias Agrarias de la Universidad Nacional del Centro del Perú

\begin{abstract}
RESUMEN
La agroforestería pecuaria se presenta como una alternativa para la ganadería sostenible, por tanto el objetivo del estudio fue determinar el rendimiento productivo, en tres periodos postpoda de uniformización y determinar la composición de nitrógeno y fibra cruda del forraje de Bolaina Blanca, cultivada como banco de proteína. El estudio se realizó en la provincia de Satipo, departamento de Junín, a una altitud de 674 msnm, en el área experimental de la Facultad de Ciencias Agrarias - Satipo. Se trabajó con 90 plantones de Bolaina Blanca, que tenían una edad de 26 meses post instalación, distribuidas en 9 unidades experimentales con 10 plantones cada una. La variable independiente fue el Periodo post poda de uniformización: tratamiento 1; 30 días post poda; tratamiento $2 ; 60$ días postpoda y tratamiento $3 ; 90$ días postpoda. Las variables dependiente fueron : Rendimiento de forraje verde, rendimiento de materia seca, y composición porcentual de nitrógeno y fibra cruda del forraje. Se uso el análisis de varianza mediante un diseño de bloques completo al azar, haciendo uso de la prueba de Duncan a un nivel de significación de 0.05 . El mejor rendimiento productivo de Bolaina Blanca se consiguió a los 30 días postpoda de uniformización con 19.82 y 3.97 gramos por planta de forraje verde y materia seca respectivamente. Los rendimientos a 30, 60 y 90 días postpoda de uniformización fueron en la época seca, de la zona. El contenido de proteína y fibra cruda fue de $16.9 \%$ y $25.3 \%$ respectivamente.
\end{abstract}

Palabras clave: bolaina, forraje, rendimiento.

\section{PRODUCTIVE YIELD, NITROGEN AND RAW FIBER OF THE FORAGE OF WHITE BOLAINA (GUAZUMA SP.) CULTIVATED AS PROTEIN BANK, IN SATIPO}

\begin{abstract}
The cattle agro forestry is presented as an alternative sustainable cattle rising; therefore, the objective of the study is to determine the productive yield during three periods post uniformity trimming, and to determine the nitrogen composition and raw fiber of the white Bolaina's forage, cultivated as a protein bank. This study was carried out in the county of Satipo, department of Junín, at 674 meters above sea level, in the Experimental Area of the Agricultural Sciences Faculty in Satipo. For the study, 90 Bolaina Blanca seedlings were used, that aged 26 months post installation, distributed in 9 experimental units, each one of them with 10 seedlings. The independent variable was the post uniformity trimming period: treatment 1 . 30 days post trimming; treatment 2, 60 days post trimming, and treatment 3, 90 days post pruning. The dependent variables were: yield of green forage, yield of dry matter, and the forage's composition percentage of nitrogen and raw fiber. The variance analysis was used by a complete randomly blocks' design, making use of the Duncan test at a significance level of 0.05 . The best productive Bolaina yield was obtained at the 30 days post uniformity trimming, with 19.82 and 3.97 grams per green forage plant and dry matter respectively. The yields at 30,60 and 90 days post uniformity was during dry times of the area. The protein content and raw fiber was $r 6.9 \%$ and $25.3 \%$ respectiely.
\end{abstract}

Key Words: bolaina, forage, yield.

\footnotetext{
* Este trabajo de investigación fue recibido el 20/03/2009 retornado para su revisión 26/10/2009 y aprobado para su publicación 16/11/2009

1 Email: lbazan2@hotmail.com

2Email: mgranados@uncp.edu.pe
} 


\section{INTRODUCCIÓN}

La Bolaina Blanca tiene fines maderables, sin embargo poco se conoce sobre su utilidad en la conservación de suelos y alimentación para el ganado, bajo la modalidad de bancos de proteína y sistemas de agroforestería pecuaria.

Por agroforestería se entiende tradicionalmente todos aquellos sistemas donde hay una combinación de especies arbóreas con especies arbustivas o herbáceas, generalmente cultivadas. Este término es muy amplio pues incluye desde la simple presencia de algunos árboles (ejemplo frutales) en combinación con cultivos de vegetales 0 cereales, hasta sistemas complejos con múltiples especies en varios estratos (Sánchez M.S. 2000).

Araya B.J. (1994) refiere que la Guasuma ulmifolia está ampliamente distribuida a través del Caribe, México y América Central y del Sur, es usada para postes, carpintería en general, construcciones ligeras y carbón. Es una importante fuente de forraje para el ganado en muchas áreas, particularmente durante la estación seca, cuando los pastos son escasos. Alcanza hasta $30 \mathrm{~m}$ de altura y entre 30 a $40 \mathrm{~cm}$. de diámetro y posee una copa en forma redonda. Las hojas son alternas de forma aovada o lanceolada de 5 a $7 \mathrm{~cm}$. de largo y 2 a $5 \mathrm{~cm}$. de ancho, las flores son marrón amarillento y tienen forma de racimo, las semillas son negras.

La Guasuma ulmifolia crece en suelos aluviales arcillosos, y en climas humados y secos; es una especie pionera que crece mejor a plena luz solar, coloniza áreas recientemente alteradas también se le encuentra creciendo a orillas de arroyos y en pasturas. Crece mayormente en elevaciones por debajo de los $400 \mathrm{~m}$ con temperatura promedio de $24{ }^{\circ} \mathrm{C}$; crece bien en áreas con una caída pluvial anual de hasta $2500 \mathrm{~mm}$. Puede ser establecida por plantado directo con semillas, 0 plantado con estacas, troncones de raíz o plántulas a raíz desnuda, las semillas necesitan ser escarificadas antes de ser plantadas, (Araya B.J.1994).

El forraje y fruto sirven de alimento a los polluelos, y las hojas al gusano de seda. El aceite de las semillas sirve para la fabricación de jabones. En áreas secas es una fuente de forraje para el ganado, pues se utilizan tanto los frutos verdes como las hojas; el contenido de proteína cruda de hojas jóvenes y tallos es de 16 a $23 \%$ y 7 a $8 \%$, respectivamente. La madera de esta especie es ampliamente utilizada para leña y carbón, postes, construcciones rurales, cajas, culatas para armas de fuego, aros, pequeñas embarcaciones, hormas para zapatos, instrumentos musicales, mangos para herramientas, e implementos agrícolas. En carpintería y ebanistería, para partes de molinos, muebles y gabinetes, túneles. Se recomienda para la fabricación de pisos, marcos para puertas y ventanas, artículos torneados y decorativos. La infusión que se obtiene del cocimiento de la corteza se utiliza en medicina casera como remedio para la lepra, elefantiasis, paludismo, afecciones cutáneas y sifilíticas Otros usos medicinales son para resfriados, enfermedades gastrointestinales como diarrea, disentería, para aliviar la fiebre y la malaria Las semillas son comestibles, frescas 0 cocidas. De los tallos jóvenes se obtienen cuerdas y cordeles; $y$ las flores tienen potencial melífero, (REFOLASA 2008).

Bazán A.L. y Granados M.M. (2007 a) con el objetivo fue demostrar la instalación de bancos proteicos de Bolaina blanca (Guazuma $s p$ ) y determinar el comportamiento productivo bajo condiciones de cultivo en limpio y sombra parcial, con fines de mejorar la alimentación de ganado. Se utilizó 180 plantones con altura inicial de $38 \pm 11 \mathrm{~cm}$. Se instaló en dos lugares: a). Instalación en área deforestada "en limpio" y b). Instalación en área reforestada con árboles de Eucaliptos torrelyana "sombra parcial". La distancia entre plantones y filas fue de $0.25 \mathrm{~cm}$., haciendo 2 filas que contenían 10 plantones por parcela, cada una de ellas rodeada de un área de libre $1.0 \mathrm{~m}$ para siembra de pasto de estrato bajo. La densidad estimada fue de 26667 plantones por hectárea. Se demostró que es posible la instalación de bancos de proteína de Bolaina blanca en áreas deforestadas en limpio. El comportamiento de las plantas, la altura, diámetro basal, número de ramas por planta, producción de materia verde y materia seca, así como la sobrevivencia, a los 13 meses de instalación, fueron estadísticamente superiores $(p<0.05)$ para el banco de proteína instalado en un área deforestada en limpio, en relación al banco instalado bajo sombra parcial, demostrando la incompatibilidad con árboles de Eucaliptus torrelyana y la sensibilidad de la Bolaina blanca a la escasez de luz solar. 
Bazán A.L. y Granados M.M. (2007 b), determinaron la altura adecuada de poda en un banco de proteína de bolaina blanca a una densidad estimada de 26667plantas por hectárea, obtuvieron rendimientos de 144.7, 102.87 y 125.07 gramos de forraje verde por planta; 36.63, 29.1336 .63 gramos por planta de materia seca; $26.4 \%, 28.95 \%$ y $29.28 \%$ de materia seca, para las alturas de poda de 0.60, 0.801 .20 metros respectivamente. Encontraron mejor respuesta en las alturas de 0.60 y 1.2 metros de altura de poda.

En tal sentido la Bolaina Blanca dentro de un sistema de agroforesteria pecuaria, se presenta como una alternativa sostenible, sin embargo dentro de ella es necesario realizar múltiples investigaciones, por ejemplo los bancos de proteína son importantes para mejorar la alimentación de ganado sin perjudicar el entorno medio ambiental de nuestra amazonia, por ello el planteamiento del problema a investigar es el siguiente: ¿Cuál es el rendimiento productivo, composición de nitrógeno y composición de fibra cruda del forraje de Bolaina Blanca cultivada como banco de proteína?.

El objetivo del estudio fue determinar el rendimiento productivo, composición de nitrógeno y composición de fibra cruda del forraje de Bolaina Blanca cultivada en banco de proteína.

\section{MATERIAL Y MÉTODOS}

El estudio se realizó en la provincia de Satipo, departamento de Junín, a una altitud de 674 msnm; una temperatura media de 24 a.C.; precipitación promedio anual de $1552 \mathrm{Mm}$., y una humedad relativa media de 70\%. Específicamente el área experimental se encuentra en el Campus Universitario de la facultad de Ciencias Agrarias - Satipo. La investigación fue de enfoque cuantitativo; aplicada; explicativa, y experimental. La población fue de 90 plantones de Bolaina Blanca, las que tenían una edad de 26 meses postinstalación. La muestra estaba constituida por la totalidad de plantas por periodo de corte. La variable independiente fue el periodo postpoda de uniformización con los siguientes tratamientos: T1, 30 días postpoda; T2: 60 días post poda; y T3: 90 días postpoda. Las variables dependientes fueron rendimiento de forraje verde, rendimiento de materia seca, y composición porcentual de nitrógeno y fibra cruda del forraje. Se trabajó con 9 unidades experimentales, cada una de ellas conformada por 10 plantones, las unidades de muestreo por cada unidad experimental fue de 5 plantones a los 30 días, 5 plantones a los 60 días y 5 plantones a los 90 días postpoda de uniformización. Se usó el análisis de varianza mediante un diseño de bloques completo al azar, haciendo uso de la prueba de Duncan a un nivel de significación de 0.05 .

\section{RESULTADOS}

\section{Producción de forraje verde:}

La producción de forraje verde de Bolaina Blanca se muestra en el Cuadro 1 en tres bloques, y los promedios se muestran en el Cuadro 2. Los promedios nos indican que la producción de forraje verde en gramos por planta fue mayor a los 30 días postcorte de uniformización, el cual es estadísticamente similar a la producción de 60 días, pero estadísticamente diferente a la producción de 90 días postcorte de uniformización $(p<0.05)$.

REFOLASA: Reforestadora Latinoamericana S.A.

Cuadro 1: Producción de forraje verde de Bolaina Blanca (g/planta), a 30, 60 y 90 días post poda de uniformización de los diferentes bloques.

\begin{tabular}{cccc}
\hline BLOQUES & \multicolumn{3}{c}{ TRATAMIENTOS } \\
\hline & T1 & T2 & T3 \\
I & 10.25 & 7,8 & 4.7 \\
II & 27 & 24.95 & 14 \\
III & 22.2 & 12,7 & 13.85 \\
\hline
\end{tabular}

Cuadro 2: Prueba de comparación de promedios de la producción de forraje verde de Bolaina Blanca (g/planta), a 30, 60 y 90 días post poda de uniformización.

\begin{tabular}{cccc}
\hline INDICADOR & \multicolumn{3}{c}{ TRATAMIENTOS } \\
\hline & T1 & T2 & T3 \\
$\begin{array}{c}\text { Forraje verde } \\
\text { g/planta }\end{array}$ & $19.82 \mathrm{a}$ & $15.15 \mathrm{ab}$ & $10.85 \mathrm{~b}$ \\
\hline
\end{tabular}


Valores con letras diferentes son estadísticamente diferentes $(p<0.05)$ según la prueba de Duncan

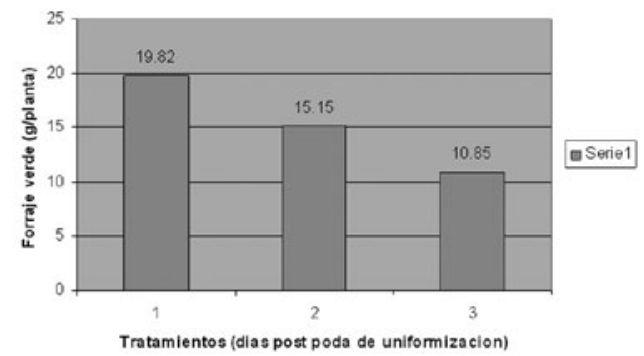

Grafico 1: Producción de forraje verde de Bolaina Blanca, a 30, 60 y 90 días post poda de uniformización.

\section{Producción de materia seca:}

La producción de materia seca de Bolaina Blanca se muestra en el Cuadro 3 en tres bloques, y los promedios se muestran en el Cuadro 4. Los promedios nos indican que la producción de forraje verde en gramos por planta a los 30, 60 y 90 días postcorte de uniformización, fueron estadísticamente similares $(p<0.05)$. Sin embargo numéricamente fue mayor a los 30 días postcorte de uniformización, seguido de la producción a los 60 días, y 90 días postcorte de uniformización.

Cuadro 3: Producción de materia seca de Bolaina Blanca (g/planta), a 30, 60 y 90 días postpoda de uniformización en diferentes bloques.

\begin{tabular}{cccc}
\hline BLOQUES & \multicolumn{3}{c}{ TRATAMIENTOS } \\
\hline I & A & B & C \\
II & 2.25 & 3.1 & 1.4 \\
III & 5.9 & 5.2 & 2 \\
& 3.75 & 3.8 & 3.8 \\
\hline
\end{tabular}

Cuadro 4: Prueba de comparación de promedios de la producción de materia seca de Bolaina Blanca (g/planta), a 30, 60 y 90 días postpoda de uniformizacion.

\begin{tabular}{lccc}
\hline INDICADOR & \multicolumn{3}{c}{ TRATAMIENTOS } \\
\hline & $\mathrm{T} 1$ & $\mathrm{~T} 2$ & $\mathrm{~T} 3$ \\
$\begin{array}{c}\text { Forraje verde } \\
\text { g/planta }\end{array}$ & $3.97 \mathrm{a}$ & $4.03 \mathrm{a}$ & $2.4 \mathrm{a}$ \\
\hline
\end{tabular}

Valores con letras diferentes son estadísticamente diferentes $(p<0.05)$ según la prueba de Duncan

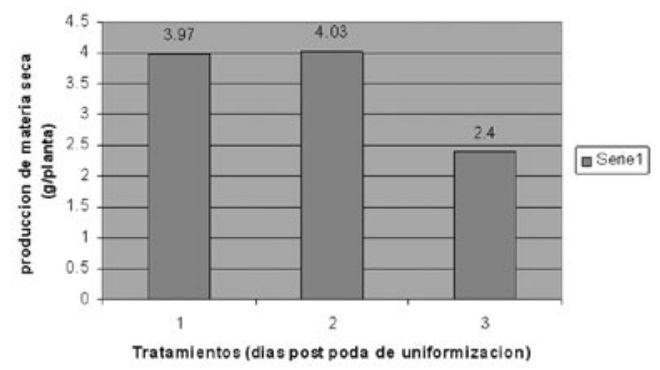

Gráfico 2: Producción de materia seca de Bolaina Blanca, a 30, 60 y 90 días postpoda de uniformización.

Proteína y fibra cruda: La evaluación de proteína y fibra cruda se realizó a los 30 días postcorte de uniformización, los resultados fueron un contenido de $16.9 \%$ de proteína y $25 \%$ de fibra cruda, tal como se muestra en el Cuadro 5.

Cuadro 5. Contenido de Proteína y Fibra Cruda de Bolaina Blanca, a 30 días postpoda de uniformización.

\begin{tabular}{cc}
\hline INDICADOR & \% base seca \\
\hline Proteína & 16.9 \\
Fibra Cruda & 25.3 \\
\hline
\end{tabular}

\section{DISCUSIÓN}

La mayor producción de forraje verde a los 30 días postcorte de uniformización, se debería a que esta evaluación se realizó en el mes de junio donde aun existen residuos de humedad en el suelo, y las evaluaciones a 60 a 90 días fueron realizadas en los meses de julio y agosto respectivamente, época en donde las lluvias disminuyen notablemente, de ahí la menor producción, nuestros resultados son inferiores al reportado por Bazán A.L. y Granados, M.M. (2007 b) probablemente por deficiencias en el mantenimiento, la competencia de malezas, y por la época seca.

Los resultados de producción de materia seca por planta, se deberían a que la evaluación a los 30 días postcorte de uniformización fue en el mes de junio 
donde aun existen residuos de humedad en el suelo, y las evaluaciones a 60 a 90 días fueron realizadas en los meses de julio y agosto respectivamente, época en donde las lluvias disminuyen notablemente, de ahí la menor producción. La materia seca no disminuye tan bruscamente como sucede en el forraje verde, por tal razón no existió diferencia entre los tres tratamientos. Nuestros resultados son inferiores a los encontrados por Bazán A.L. y Granados, M.M (2007 b) quienes evaluaron en época lluviosa.

Nuestros resultados de proteína se encuentran dentro del rango de REFOLASA (2008), quien reporta que; el contenido de proteína cruda de hojas jóvenes y tallos es de 16 a $23 \%$ y 7 a $8 \%$, respectivamente, información de fibra cruda aun parece no ser disponible.

\section{CONCLUSION}

- El mejor rendimiento productivo de Bolaina Blanca, se consiguió a los 30 días postpoda de uniformización con 19.82 y 3.97 gramos por planta de forraje verde y materia seca respectivamente. El bajo rendimiento en relación a otros reportes, fue debido a que las evaluaciones se realizaron entre junio y agosto, época seca en la zona. El contenido de proteína y fibra cruda fue de $16.9 \%$ y $25.3 \%$ respectivamente.

\section{LITERATURA CITADA}

Araya B. J. 1994. Identificación y caracterización de árboles y arbustos con potencial forrajero en Puriscal. Costa Rica: Centro Agronómico Tropical de Investigación y Enseñanza (CATIE).

Bazán A.L.; Granados M.M. 2007a. Establecimiento de Bancos Proteicos de Bolaina Blanca (Guazuma sp): Una Alternativa para la alimentación de ganado en selva. IIFCAS Universidad Nacional del Centro del Perú; Huancayo.

Fundación CIPAV. 2004. Proyecto Enfoques silvopastoriles integrados para el manejo de ecosistemas. Centro Agronómico Tropical de Investigación y Enseñanza (CATIE), Costa Rica. (Fecha de acceso 10 de diciembre 2007), URL Disponible en: http://www.cipav.org. co/redagrofor/proinvde/RPBM.htm.

Sánchez M.S. 2000. Sistemas agroforestales para intensificar de manera sostenible la producción animal en América Tropical. Roma: FAO.

REFOLASA. 2008. (Fecha de acceso 12 de diciembre 2008) Bolaina. Disponible en:

http://www.refolasa.com/archivos/r_bolaina. jpg\&imgrefurl. 